\title{
Пространственный образ Тувы в объективе социокультурной феноменологии"
}

\author{
Юрий В. Попков \\ Институт философии и права Сибирского отделения Российской академии наук; \\ Новосибирский государственный технический университет, Российская Федерация,
}

Евгений А. Тюгашев

Новосибирский национальный исследовательский государственный университет, Российская Федерация
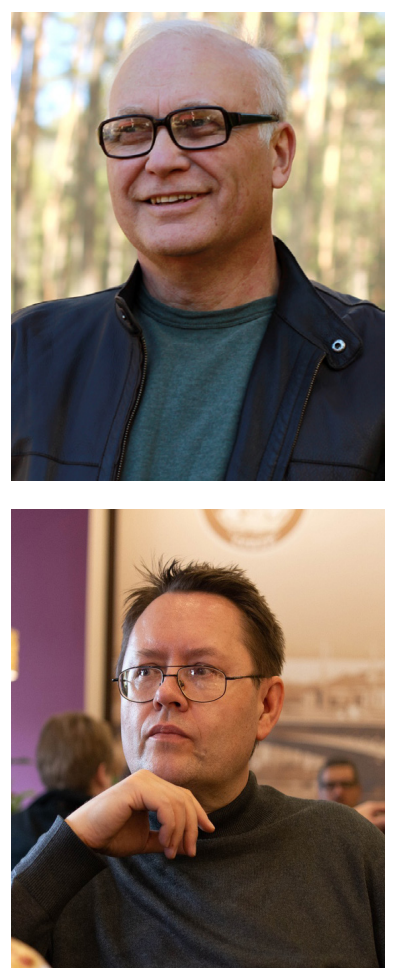

В статье обсуждается вопрос о дисциплинарной принадлежности категории «пространственное развитие», предлагается ее авторская интерпретация, эвристичность которой иллюстрируется на примере анализа пространственного образа Тувы. Предложена философема пространственного развития, которое трактуется как развитие объекта, включающее качественное преобразование (усложнение или упрощение) его внутреннего и внешнего пространства.

Анализ Тувы с точки зрения ее пространственного статуса позволяет определить ее как интегральное, но дифференцированное целое, обладающее собственной индивидуальностью. Она рассматривается как социокультурная личность, то есть индивидуально определенное единство территории, народонаселения и его социокультурного облика.

По критерию контактности/неконтактности пространственной культуры Туву можно отнести к «неконтактным» культурам. Ее смещение в данном континууме по направлению к большей контактности происходит вследствие демографического роста, транспортнопромышленного освоения территории, перехода к оседлому образу жизни и урбанизации, расширения межрегиональных и международных связей. По критерию локальности/магистральности Тува представляет локальную культуру. До сих пор она сохраняет свою культурную самобытность и ориентируется на сотрудничество со всеми соседними магистральными культурами (российской, монгольской, китайской). Взаимодействие с магистральными культурами не привело к распространению тувинцев по обширным территориям. Это признак того, что культура тувинцев может быть отнесена к медиальным (срединным), центрированным на себе типам. Пограничное положение Тувы межу Россией и Китаем дает основание для определения ее в качестве разновидности фронтирных территорий - лимитрофов.

Ключевые слова: социокультурная феноменология; пространственное развитие; пространство; пространственный поворот; социокультурная личность; этнокультура; Тува; неконтактная культура; локальная культура; медиальная культура; лимитроф

"Работа выполнена по программам фундаментальных научных исследований, определяемых Президиумом РАН.

\section{Для цитирования:}

Попков Ю. В., Тюгашев Е. А. Пространственный образ Тувы в объективе социокультурной феноменологии [Электронный ресурс] // Новые исследования Тувы. 2019, № 3. URL: https://nit.tuva.asia/nit/article/view/860 (дата обращения: дд.мм.гг.). DOI: 10.25178/nit.2019.3.1

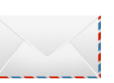

Попков Юрий Владимирович - доктор философских наук, профессор, главный научный сотрудник отдела социальных и правовых исследований Института философии и права Сибирского отделения Российской академии наук; профессор кафедры международных отношений и регионоведения Новосибирского государственного технического университета. Адрес: 630090, Россия, г. Новосибирск, ул. Николаева, д. 8 . Тел.: +7 (383) 330-22-40. Эл. адрес: yuripopkov54@mail.ru ORCID ID:0000-0002-1036-9253

Тюгашев Евгений Александрович - доктор философских наук, доцент кафедры теории и истории государства и права Института философии и права Новосибирского национального исследовательского государственного университета. Адрес: 630090, Россия, г. Новосибирск, ул. Пирогова, д. 1. Тел.: +7 (383) 363-42-54. Эл. адрес: filosof10@yandex.ru ORCID ID: 0000-0001-62170601

Popkov Yuri Vladimirovich, Doctor of Philosophy, Professor; Chief Researcher, Department of Social and Legal Studies, Institute of Philosophy and Law, Siberian Branch, Russian Academy of Sciences; Professor, Department of international relations and regional studies, Novosibirsk State Technical University. Postal address: 8 Nikolaev St., 630090 Novosibirsk, Russian Federation. Tel.: +7 (383) 330-22-40. E-mail: yuripopkov54@mail.ru

Tyugashev Evgeny Alexandrovich, Doctor of Philosophy, Associate professor, Department of Theory and History of Law, Institute of Philosophy and Law, Novosibirsk National Research State University. Postal address: 1 Pirogov St., 630090 Novosibirsk, Russian Federation. Tel.: +7 (383) 269-42-54. E-mail: filosof10@yandex.ru 


\title{
(20.
}

\section{The spatial image of Tuva in the focus of sociocultural phenomenology}

\author{
Yuri V. Popkov \\ Institute of Philosophy and Law, Siberian Branch, Russian Academy of Sciences; \\ Novosibirsk State Technical University, Russian Federation, \\ Evgeny A. Tyugashev \\ Novosibirsk National Research State University, Russian Federation
}

\begin{abstract}
The article examines possible identifications of 'spatial development' as a discipline, offering its interpretation and explaining its heuristic potentional by analyzing the spatial image of Tuva. It also offers a philosophy of spatial development, which is interpreted as the development of the object, including its qualitative transformation (via either complication or simplification) of its internal and external space.

Analyzing Tuva from the point of view of its spatial status allows us to define it as an integral unit with its own internal structure and identity. It can be defined as a sociocultural subject, i.e. an individuated unity of the territory, population and its sociocultural character. According to the criterion of contact/non-contact spatial culture, Tuva can be seen as a 'non-contact' culture. Its shift towards greater contactness is due to a number of reasons, including demographic growth, transport and industry-related land development, transition to a sedentary lifestyle, urbanization, and the expansion of interregional and international relations. According to the criterion of local/ mainstream culture, Tuva is a local culture. It has been maintaining its cultural authenticity and focusing on cooperation with all neighboring cultures (such as Russian, Mongolian and Chinese). The interaction with these cultures did not lead to the spread of the Tuvans over vast territories. This is the sign that Tuvan culture is of a median type, which is focused on itself. The border position of Tuva between Russia and China gives reason to define it as a kind of frontier territory, or a limitrophe.
\end{abstract}

Keywords: sociocultural phenomenology; spatial development; space; spatial turn; sociocultural identity; ethnic culture; Tuva; noncontact culture; local culture; medial culture; limitrophe states

"The article was written under the aegis of programs of fundamental research established by the Presidium of the Russian Academy of Sciences.

For citation:

Popkov Yu. V. and Tyugashev E. A. The spatial image of Tuva in the focus of sociocultural phenomenology. The New Research of Tuva. 2019, no. 3. URL: https://nit.tuva.asia/nit/article/view/860 (access date ... ). DOI: 10.25178/nit.2019.3.1

\section{Введение}

Проблема пространственного развития является актуальной для многих стран, особенно отличающихся большими территориями и внутренним разнообразием - природно-климатическим, экономико-географическим, демографическим, этнокультурным. Россия по этим показателям принадлежит к числу явных лидеров в мире. Отражением возрастающей потребности в целенаправленном регулировании процессов в данной сфере является утверждение Распоряжением Правительства РФ от 13.02.2019 № 207-р Стратегии пространственного развития Российской Федерации на период до 2025 г. (далее - Стратегия). В ней определены принципы, приоритеты, основные направления, сценарии пространственного развития России, выделены ее макрорегионы, перспективные центры экономического роста и экономические специализации каждого из субъектов Федерации. Целью Стратегии провозглашается «сокращение межрегиональных различий в уровне и качестве жизни населения, ускорение темпов экономического роста и технологического развития» ${ }^{1}$.

Стратегия сфокусирована на двух основополагающих моментах: на региональном развитии и его экономических перспективах. Об этом свидетельствует содержание самого текста Стратегии, что в принципе соответствует имеющемуся в ней определению пространственного развития, которое понимается как «совершенствование системы расселения и территориальной организации экономики, в том числе за счет проведения эффективной государственной политики регионального

\footnotetext{
${ }^{1}$ Распоряжение Правительства РФ от 13.02.2019 № 207-р «Об утверждении Стратегии пространственного развития Российской Федерации на период до 2025 года» [Электронный ресурс] // Консультант. URL: http://www.consultant.ru/document/ cons_doc_LAW_318094/006fb940f95ef67a1a3fa7973b5a39f78dac5681/ (дата обращения: 24.02.2019).
} 
развития»1. Акцент на региональном развитии четко закреплен при формулировке статуса данного доктринального источника: «Стратегия представляет собой документ стратегического планирования, разрабатываемый в рамках целеполагания по территориальному принципу»².

В последнее время представление о пространственном развитии не ограничивается выделением его экономического и регионального аспектов. «Мир все больше переходит к пониманию ценности пространства не только в экономическом (снижение издержек, доступность тех или иных факторов производства), но и в экологическом, культурном и общечеловеческом контекстах» (Крюков, 2016: 2). С учетом данного обстоятельства в Стратегии в той или иной степени обозначаются многие важные аспекты пространственного развития, в том числе касающиеся социокультурного контекста, однако, с нашей точки зрения, не все они являются в должной мере последовательными и проработанными, отсутствует необходимая для подобного рода документов комплексность и системность. Отметим далее несколько проблемных зон, значимых для актуализации поставленной темы.

Среди основных принципов пространственного развития провозглашается необходимость учета этнокультурного фактора при обеспечении социально-экономического развития субъектов Российской Федерации, однако возможности его реализации на практике не обозначены, механизм этого учета нигде не прописан. Это же касается и провозглашенного принципа обеспечения «гарантий прав коренных малочисленных народов, включая поддержку их экономического, социального и культурного развития, защиту исконной среды обитания и традиционного природопользования и образа жизни»³. Таким образом, оба отмеченных принципа остаются декларативными.

При описании особенностей разных регионов акцентируются «различия в плотности населения» как важная проблема, в то же время качество населения, в том числе с точки зрения его этнокультурного потенциала и особенностей существующей экономической культуры, никак не учитывается.

В перечне направлений пространственного развития обозначено сохранение и восстановление биологического разнообразия, однако в отношении этнокультурного разнообразия такой цели не ставится, хотя в настоящее время это признается в качестве важной государственной задачи. Использование в Стратегии термина «культурные ландшафты» ограничивается его простым упоминанием и не имеет содержательного наполнения.

Говорится о сохранении природного и культурного наследия, содействии сохранению, возрождению и развитию народных художественных промыслов, но в составленном применительно к каждому субъекту Российской Федерации перечне перспективных экономических специализаций это нигде не фиксируется.

Таким образом, хотя в Стратегии присутствует упоминание о многих аспектах пространственного развития, содержательно оно сводится, по сути, к экономическим перспективам регионального развития. Ограниченность такого подхода чревата недостаточной практической эффективностью реализации Стратегии и свидетельствует о ее концептуальных пробелах.

За описанной конкретной ситуацией стоит важная научная проблема, касающаяся сущностной характеристики пространственного развития, решение которой должно лежать за пределами частнопредметного подхода. Задача настоящей статьи состоит в аргументации общедисциплинарной принадлежности категории «пространственное развитие», обосновании ее авторской интерпретации в контексте пространственного поворота в социокультурных исследованиях и иллюстрации ее эвристического потенциала на примере анализа пространственного образа Тувы.

\section{Пространственный поворот и социокультурные исследования}

В эпоху европейского Просвещения в философском сообществе возникло аксиологически ориентированное расхождение либеральной «партии времени» и консервативной «партии пространства» (Румянцев, 2018: 143). В центре внимания либеральной философской мысли находилась проблема времени - эпохи Нового времени, прогресса и модернизации. Национально ориентированный философский романтизм опирался на географический детерминизм, акцентировал разнообразие культур, противоборство народов гор и равнин, цивилизаций моря и суши, номадов и оседлого населения.

\footnotetext{
1 Там же.

2 Там же.

3 Там же.
} 
Радость от завершенности прогресса, предчувствие конца времени, конца истории и катастрофическое мироощущение стимулировали пространственный поворот в социогуманитарной мысли (The Spatial Turn ..., 2008). В феноменологическом плане поворот - это изменение перспективы и направления движения, смещение угла зрения, открывающее новые горизонты и перспективы. Пространственный поворот выразился в концептуализации ряда фиксируемых в обыденности пространственных реалий, в достижении понимания фундаментальной определенности (и взаимоограниченности) конкретных феноменов, а также в панорамной представленности возможностей движения.

В социокультурных исследованиях пространственный поворот обозначил П. А. Сорокин, который обратился к теме массовых перемещений индивидов в социальном и культурном пространствах. Он зафиксировал культурный эффект перемены «душ» и «костюма поведения», наблюдающийся при смене социальной позиции (Сорокин, 2005: 257-258). Наряду с этим, культурный багаж П. А. Сорокин рассматривал как ресурс вертикальной социальной мобильности.

В социокультурной теории А. С. Ахиезера большое значение придается дифференциации локальных сообществ и больших обществ (Ахиезер, 1998). На его взгляд, некоторые народы (например, славяне) склонны к локализму, к проживанию в небольших замкнутых мирах, мало зависящих друг от друга. Агрегация локальных сообществ в большое сообщество происходит благодаря иноэтничным группам и является неустойчивой, периодически распадающейся. Основой устойчивого существования большого общества выступает, по мнению А. С. Ахиезера, либеральная культура, ориентированная на ценность государства как всеобщего, права и рынка, диалога и медиации, компромисса. В будущем ему видится образование сверхбольшого общепланетарного общества.

Эксплицируя содержание социокультурного подхода, В. П. Фофанов зафиксировал такие моменты пространственности как структурная дифференцированность, количественная определенность, ограниченность отдельного, его существование во внешнем пространстве, состоящем из множества иных отдельных объектов, ограничивающих друг друга, но связанных взаимодействиями и взаимопереходами (Фофанов, 1986). В социокультурном плане отдельный социальный организм рассматривается как специфическая этнокультура, развивающаяся на основе межкультурных взаимодействий. В тенденции эти взаимодействия ведут к интеграции этнокультур.

Таким образом, в социокультурных исследованиях раскрывается внутреннее и внешнее пространство социальных организмов, учитывается эффект масштаба и интеграции через механизм межкультурных взаимодействий. Но картина взаимообусловенного развития множества отдельных социальных организмов не дает представления о пространственном развитии.

\section{Концеетт пространственного развития}

В официальных документах, как отмечалось, пространственное развитие непосредственно отождествляется с территориальным развитием, то есть с развитием территории. Поскольку категория «территориальное развитие» традиционно является категорией экономической географии (Лаженцев, 2013: 10), то логично возникает вопрос о дисциплинарной принадлежности категории «пространственное развитие» и ее содержании.

По мнению А. Н. Головкова, пространственное развитие является экономической категорией, учитывающей не только административное деление, но и макрорегиональное деление, а также межрегиональные и трансграничные отношения (Головков, 2011: Электронный ресурс). Впрочем, он тут же отмечает, что, «несмотря на использование в терминологии понятий “пространство” и “пространственный”, область исследований осталась в рамках традиционного территориального подхода» (там же). Следовательно, экономико-географическая интерпретация сохранила влияние, а более общее понятие пространственного развития осталось несформированным.

В. Н. Лаженцев предложил соотносить пространственное развитие и территориальное развитие как общее и часть (Лаженцев, 2013: 18). Категория пространственного развития, как он полагает, описывает многообразные формы материального и духовного мира (там же: 14). Можно предполагать, что в данной интерпретации пространственное развитие - это общенаучная и философская категория. Но автор к такому выводу не приходит. На наш же взгляд, за категорией пространственного развития следует признать философский статус. 


\section{Философема пространственного развития}

Концепция пространственного развития, очевидно, исходит из трактовки пространства как объективной характеристики сущего. Следовательно, субъективистская интерпретация пространства как формы переменчивого созерцания в данном случае не приемлема. Целесообразно обратиться к объективистским трактовкам пространства.

Как известно, все философские концепции пространства делятся на субстанциальные и реляционные. Для анализа пространственного развития необходимо сделать выбор между этими двумя базовыми концепциями.

В рамках субстанциальной концепции пространства оно рассматривается как особая сущность, например, как пустота, вмещающая все тела. При подобном субстанциональном понимании пространства о его развитии говорить не приходится. Поэтому в данном случае концепт пространственного развития онтологически невозможен.

Реляционная концепция пространства базируется на понимании его в качестве особого отношения между объектами. Связанные определенными отношениями, объекты составляют единый, более сложный объект. Поэтому можно говорить и о развитии объекта, и о развитии пространства объекта, и о пространственном развитии объекта. Иначе говоря, пространственное развитие есть развитие объекта, включающее качественное преобразование (усложнение или упрощение) его внутреннего и внешнего пространства.

Итак, пространство можно определить как сеть отношений сосуществования моментов движения объекта. В непрекращающемся движении последующее существует наряду с предыдущим, которое является его предпосылкой. Поэтому наряду с субординацией возникает координация сущего - сосуществование порядков непрекращающихся волн движения. Порядки наслаиваются друга на друга, конституируя слои сущего. Поскольку наслоение осуществляется в некотором порядке, то движущийся объект есть порядок порядков. В ходе развития происходит преобразование этих порядков, что понимается как пространственное развитие.

Тенденцией пространственного развития является усложнение объекта, что дает основание для отождествления пространственного развития с прогрессивными изменениями в пространственной организации. Но развитие, наряду с прогрессом как движением вперед, от низшего к высшему, включает и сопутствующую контртенденцию - регресс, возвращение назад, упрощение и ограничение движения объекта. Этот эффект хорошо иллюстрирует феномен архаизации общества в период современных социальных трансформаций (Ламажаа, 2011). Взаимосвязь прогресса и регресса открывает темпоральный горизонт пространственного развития.

\section{Коррелятивная философема темпорального развития}

В связи с использованием категории «пространственное развитие» обращает на себя внимание отсутствие в научно-философском дискурсе парной категории «временно́е развитие», хотя, несомненно, что существует темпоральное развитие - развитие темпоральности, темпоральных отношений и структур.

Наглядным примером темпорального развития является модернизация. Последняя понимается не просто как обновление объекта. Модернизация подразумевает приведение характеристик объекта в соответствие с аналогичными характеристиками более развитых объектов. Это интерпретируется как достижение состояния модерна, современности.

Эталонами современности могут служить различные, одновременно существующие объекты. Столь же различны исторически отправные пункты развития. Поэтому возможны различные модели модернизации для одной и то же страны. Разнообразие моделей, обусловленное ориентацией на те или иные эталоны современности, умножается вариабельностью процессов архаизации, сопутствующих избранной модели модернизации.

Зачастую возврат в прошлое невозможен из-за исчерпанности ресурсов, использовавшихся на архаической стадии развития. Это объективно ограничивает множество допустимых моделей модернизации. Наряду с этим сохраняется пространство для маневра, обусловленное разнообразием эталонов современности.

Темпоральный маневр можно рассматривать как ориентир в анализе перспектив пространственного развития. Последнее жестко ограничено наличными ресурсами. И важнейшим таким ресурсом явля- 
ется исходный пространственный статус. Предложим далее вариант диагностики пространственного статуса на примере Тувы как весьма интересного для анализа в заданном контексте региона.

\section{Социокультурная личность Тувы}

Прежде всего возникает вопрос: что есть Тува с точки зрения ее пространственного развития? Очевидно, что когда говорят о Туве и ее пространственном развитии, то подразумевают сразу несколько значимых составляющих: она есть отдельный географический регион, обладающий определенным административно-государственным статусом и особой структурой населения с абсолютным доминированием тувинского народа, отличающегося высоким уровнем сохранности традиционной культуры. Следовательно, Тува есть интегральное, но дифференцированное целое, обладающее собственной индивидуальностью, которую можно назвать социокультурной личностью.

Философско-исторический концепт социокультурной личности вводится нами на основе социокультурного подхода П.А.Сорокина, который считал неразделимой триадой личность, общество и культуру. При этом мы учитываем ряд концептуальных предпосылок. Во-первых, это то обстоятельство, что П.А. Сорокин различал индивида и личность, а последнюю характеризовал как социум (Сорокин, 1992: 218). Во-вторых, это признанный в общественных науках и философии истории концепт коллективной (социальной) личности, в частности, государства как публичного лица, включающего в качестве составных элементов власть, население и территорию. В-третьих, это опыт евразийской интерпретации России-Евразии как симфонической многонародной личности. Социокультурная личность есть индивидуально определенное единство территории, народонаселения и его социокультурной организации.

Тува может быть представлена в качестве соборной личности с точки зрения традиционного мировоззрения. По наблюдению Г. Н. Потанина, отдельные элементы ландшафта (горы, скалы, вода, лес, степь) со своими особыми духами мыслятся как составляющие урочищ, с их самостоятельной жизнью и собственными душами. А отдельные урочища со своими мелкими духами объединяются в дух страны и т. д. (Потанин, 2002: 28).

Удачный вариант социокультурной персонификации предложен И. С. Тарбастаевой, сравнившей Туву с «дикаркой, первозданную красоту которой могут увидеть лишь самые смелые и храбрые, те, кто приедет в этот относительно изолированный и удаленный от остального мира край» (Тарбастаева, 2014: Электр. ресурс).

\section{Тува в ряду контактных и неконтактных культур}

Показательно, что приведенная в качестве примера персонификация Тувы включает характеристику ее пространственного статуса, а также пространственного поведения как социокультурной личности. Эта характеристика позволяет отнести Туву к «неконтактным» культурам. Представители данных культур общаться предпочитают дистанционно, без тесного соприкосновения (Hall, 1990). Типичен в этом отношении тувинский синдром безмолвия, выделяемый этнопсихологом Т. А. Ондар⒈

Как хорошо известно специалистам, к народам с неконтактной культурой относят североамериканцев, англичан, немцев, скандинавов, русских, китайцев, японцев и др. Дифференцированные по степени контактности/неконтактности пространственные культуры народов мира располагаются в определенном континууме, сдвиг в рамках которого можно рассматривать как вектор пространственного развития.

Смещение Тувы в данном континууме по направлению к большей контактности неизбежно происходит вследствие демографического роста, транспортно-промышленного освоения территории, перехода к оседлому образу жизни и урбанизации, расширения межрегиональных и международных связей. Как показывает исторический опыт пространственного развития неконтактных культур, формы и механизмы повышения степени контактности разнообразны. В частности, это ритуализация и формализация повседневного общения (в том числе, через актуализацию традиционного национального этикета), разграничение и огораживание территорий, организованная трудовая эмиграция и делегирование групп для культурного обмена.

${ }^{1}$ Тувинский этикет - это практично (2011) [Электронный ресурс] // Плюс Информ. 17 февраля. URL: http://plusinform.ru/ main/2309-tuvinskiy-etiket-\%E2\%80\%93-eto-praktichno.html (дата обращения: 24.02.2019). 
Противопоставление контактных и неконтактных культур можно использовать не только для построения детального проксемического профиля Тувы. Данное противопоставление определяет более общий методологический ориентир, состоящий в обращении к дуальным моделям культуры как инструменту характеристики пространственного статуса Тувы.

\section{Локальность тувинской культуры}

Одной из дуальных моделей культуры является противопоставление локальных и магистральных культур (Головнёв, 2012). Каждая из них реализует специфические модели пространственного поведения. Локальная культура ориентирована на освоение конкретного биотопа и характеризуется умением в нем выживать. Магистральная культура - культура больших пространств - ориентирована на мобильность, посредничество и экспансию. Она осваивает социокультурные ресурсы самих локальных культур, синтезирует их в сети коммуникаций и сложные сообщества. Магистральная культура - это фактически совокупность локальных культур, в которых одна из локальных культур выступает гегемоном-лидером и интегратором локальных культур, оказавшихся на ее пути.

Российскую государственность А. В. Головнёв описывает как синтез, в котором магистральная культура норманнов и локальные культуры славян взаимно усиливали друг друга (Головнёв, 2009: 421). Аналогичный эффект наблюдался во взаимодействии славян с православно-византийской и монгольской магистральными культурами.

Традиционно тувинцы вели кочевой образ жизни. Но сезонные кочевания в условиях Тувинской котловины проходили обычно на недалекие расстояния по вертикали (Прокофьева, 2011: 168). Современные тувинцы в своем большинстве отличаются сравнительно слабой миграционной подвижностью, привычкой к определенным условиям труда и быта, привязанностью к родительскому дому и родным местам (Анайбан, 2011: Электр. ресурс). Эти признаки позволяют идентифицировать тувинскую культуру как локальную культуру.

На протяжении своей истории тувинцы вступали во взаимодействие с несколькими магистральными культурами - монгольской, китайской (точнее, маньчжурской) и российской. Описываемый А. В. Головнёвым эффект взаимного усиления устойчиво проявлялся, по-видимому, только во взаимодействии с российской культурой, что в XX веке обеспечило многократный рост численности тувинцев.

Но при этом не предвидится формирование синтетической российско-тувинской культуры. Тува сохраняет свою культурную самобытность и ориентируется на сотрудничество со всеми соседними магистральными культурами.

\section{Медиальность тувинской культуры}

В отличие от модели, существующей у славян, взаимодействие с магистральными культурами не привело к распространению тувинцев по обширным территориям. Это признак того, что культура тувинцев не является латеральной культурой. Соответственно, она может быть отнесена к противоположному типу этнокультуры, который Э. Смит называл вертикальной (или демотической) культурой (Smith, 1986). С учетом сложившейся терминосистемы последний тип этнокультуры удобнее определить как медиальный (срединный), центрированный на себе тип.

Выделяемые Э. Смитом признаки латеральных и медиальных этнокультур (там же: 76-89) мы систематизировали и представили в виде сравнительной табличной матрицы (табл.).

Э. Смит детально не описывал особенности экономической организации аристократических и демотических этносов. Он только подчеркивал болезненную реакцию демотических этносов на давление урбанизации и торговли. На его взгляд, для национального возрождения демотического этноса важна мобилизация, достигаемая решением ряда задач (Smith, 2003: 720), которые, на наш взгляд, могут быть соотнесены с отдельными сферами экономической жизни:

- в сфере жизнеобеспечивающей экономики - решение задачи выживания народа;

- в сфере престижной экономики - восстановление достоинства народа, раскрытие его уникальности;

- в сфере моральной экономики - помещение народа («масс») в центр государственной озабоченности;

- в сфере традиционной (статусной) экономики - самоорганизация этноса как единой автономной территориальной общины, распоряжающейся своей судьбой на своей собственной территории (родине), контролирующей свои собственные ресурсы. 
Таблица. Сравнительная характеристика признаков латеральных и медиальных культур, по Э. Смиту Table. A comparison between the characteristics of lateral and medial cultures, according to A. Smith

\begin{tabular}{|c|c|}
\hline Латеральные этносы (культуры) & Медиальные этносы (культуры) \\
\hline $\begin{array}{l}\text { Хетты, персы, ассирийцы, римляне, арабы периода } \\
\text { халифата и монголы периода империи, норманны, } \\
\text { османы, англосаксы, французы, русские, испанцы }\end{array}$ & $\begin{array}{l}\text { Шумеры, ирландцы, баски, курды, шотландцы, венгры, } \\
\text { поляки, греки, евреи, армяне, сикхи, сингалы, тибетцы, } \\
\text { друзы, копты, эфиопы, швейцарцы, каталанцы, пле- } \\
\text { менные арабы, монголы }\end{array}$ \\
\hline $\begin{array}{l}\text { Границы их местообитания широкие, нечеткие и } \\
\text { разреженные. Зачастую они проживают на широких } \\
\text { равнинах. }\end{array}$ & $\begin{array}{l}\text { Местообитание компактное, четко выделенное. За- } \\
\text { частую они проживают в изоляции или труднодос- } \\
\text { тупных районах. }\end{array}$ \\
\hline $\begin{array}{l}\text { Горизонтальные, открытые и легкодоступные, эк- } \\
\text { стенсивно расширяющиеся, охватывающие и подчи- } \\
\text { няющие себе локальные вертикальные этносы в } \\
\text { деспотиях и империях }\end{array}$ & $\begin{array}{l}\text { Вертикальные, закрытые и труднодоступные, с высо- } \\
\text { кими культурными барьерами и слабо ассимилируемые } \\
\text { латеральными этносами, с интенсивной эмоциональ- } \\
\text { ной жизнью }\end{array}$ \\
\hline $\begin{array}{l}\text { Аристократические, с многоуровневой иерархией } \\
\text { (каст, сословий, классов), но полиэтничной элитой }\end{array}$ & $\begin{array}{l}\text { Демотические, с мозаичной социальной структурой, } \\
\text { консолидированные харизматичными лидерами на } \\
\text { основе чувства избранности и коллективной миссии }\end{array}$ \\
\hline $\begin{array}{l}\text { Формируют «гражданско-территориальную» мо- } \\
\text { дель нации путем этнической бюрократической } \\
\text { инкорпорации и распространения культуры до- } \\
\text { минантного этноса }\end{array}$ & $\begin{array}{l}\text { Формируют «этно-генеалогическую» модель нации } \\
\text { путем героизации этнического прошлого, обращения } \\
\text { к народной культуре, родным языкам, ритуалам и } \\
\text { обычаям. }\end{array}$ \\
\hline
\end{tabular}

\section{Тува как лимитроф: от фронтира к транзиту (вместо заключения)}

Э. Смит выделяет несколько типов демотических этносов, в частности, фронтирные этносы. Пограничное положение этих этносов, по его оценке, может определяться локализацией сообщества между двумя более крупными конкурирующими государствами или цивилизациями (Smith, 1986: 84).

C XVII в. Тува стала фронтирной территорией между Россией и Китаем (Дацышен, 2014). Такие территории в настоящее время принято называть лимитрофами.

Развернутую характеристику лимитрофов дает И. Г. Яковенко: «Чаще всего это леса, лесостепи, степи, пустыни, горные страны, болотистые местности - территории со сложным континентальным климатом, зоны рискованного земледелия и экстенсивного ведения хозяйства. Иными словами, лимитроф - не самое оптимальное место для разворачивания цивилизации, в силу чего ядра локальных цивилизаций располагаются в других пространствах. Поэтому пространства лимитрофа часто оказываются своеобразными историческими отстойниками и этнокультурными изолятами. Сюда выдавливаются и здесь доживают свой век формы социальности и культуры, самые архаичные из всех, которые возможны на просторах между двумя центрами локальных цивилизаций» (Яковенко, 2006: 19).

Подобному описанию в определенной степени соответствует Тува, и в нем просматривается негативная оценка лимитрофного положения.

Наряду с этим встречаются и положительные оценки лимитрофности. Отмечается, что такие небольшие государства являются, «во-первых, областями этнокультурных контактов представителей 
различных цивилизаций, во-вторых - “буферным пространством”, их разделяющим, и, в-третьих, “рингом”, на котором они сталкиваются друг с другом» (Хатунцев, 2011: 96). По оценке Ч. К. Ламажаа, именно благодаря таким столкновениям и взаимному блокированию России, Китая, Японии и Монголии Тува смогла выжить и приобрести государственность (Ламажаа, 2014: Электр. ресурс).

Но взаимное блокирование с неизбежностью ведет, как считает монгольский публицист Баабар на примерах Монголии и Киргизии ${ }^{1}$, к блокированию зарубежных инвестиций, коррупции и политической нестабильности. В связи с этим он предлагает смириться с судьбой и не форсировать модернизацию, выжидать и ограничиваться достаточно скромным существованием, обеспечивающим выживание.

В известном отношении такова геоэкономическая реальность и для Тувы. Возможностью развития в этих условиях является транзит (Smith, 1986: 84), что и зафиксировано в Стратегии социально-экономического развития Тувы до 2030 г. ${ }^{2}$ Но это означает, что до формирования мощных транзитных транспортных коридоров и превращения Тувы в самостоятельного геоэкономического игрока едва ли стоит делать ставку на привлечение инвестиций и активное освоение природных ресурсов.

\section{СПИСОК ЛИТЕРАТУРЫ}

Анайбан, 3. В. (2011) Характеристика этнодемографических процессов Тувы в советский период [Электронный ресурс] // Новые исследования Тувы. № 2-3. URL: https://nit.tuva.asia/nit/article/view/412 (дата обращения: 24.02.2019).

Ахиезер, А. С. (1998) Россия: критика исторического опыта: социокультурная динамика России. Новосибирск : Сибирский хронограф. Т. І. От прошлого к будущему. 804 с.

Головков, А. Н. (2011) Пространственное развитие как экономическая категория [Электронный ресурс] // Управление экономическими системами. № 2 (26). URL: http://uecs.ru/uecs-26-262010/ item/325-2011-03-25-11-33-26 (дата обращения: 24.02.2019).

Головнёв, А. В. (2009) Антропология движения. Екатеринбург : УрО РАН ; Волот. 496 с.

Головнёв, А. В. (2012) Локальные и магистральные культуры Северной Евразии // Человек и Север: антропология, археология, экология / отв. ред. А. Н. Багашёв. Вып. 2. Тюмень : ИПОС СО РАН. 425 с. C. 234-237.

Дацышен, В. Г. (2014) Саянский рубеж. Южная часть Приенисейского края и русско-тувинские отношения в 1616-1911 гг. М. : Директ-Медиа. 309 с.

Крюков, В. А. (2016) Артерия или матрица? // ЭКО. № 5. С. 2-4.

Лаженцев, В. Н. (2013) Территориальное развитие как экономико-географическая деятельность (теория, методология, практика) // Экономика региона. № 1. С. 10-20.

Ламажаa, Ч. К. (2011) Архаизация общества в период социальных трансформаций // Знание. Понимание. Умение. № 3. С. 35-42.

Ламажаa, Ч. К. (2014) Тува и Россия: 100 лет вместе [Электронный ресурс] // Новые исследования Тувы. № 3. URL: https://nit.tuva.asia/nit/article/view/127 (дата обращения: 24.02.2019).

Потанин, Г. Н. (2002) Очерки Северо-Западной Монголии. Выпуск 2 // Традиционная культура тувинцев глазами иностранцев (конец XIX - начало XX века) / подгот. текстов, предисл. и коммент. А. К. Кужугет. Кызыл : Тувинское книжное издательство. 225 с. С. 18-23.

Прокофьева, Е. Д. (2011) Процесс национальной консолидации тувинцев. СПб. : Наука. 538 с.

Румянцев, О. К. (2018) Пространственный поворот: отношение этноса и нации как аналогия отношения пространственного и временного модуса субъективности человека // Целевые ориентиры государственной национальной политики: возобновление человеческого ресурса и национальные культуры: проблема Другого / под ред. О. К. Румянцева, А. Ю. Шеманова. СПб.: Алетейя. 358 с. С. 137-159.

Сорокин, П. А. (1992) Человек. Цивилизация. Общество. М. : Политиздат. 543 с.

Сорокин, П. А. (2005) Социология революции. М. : РОССПЭН. 704 с.

${ }^{1}$ Баабар. Русско-китайский след. Почему власти Монголии так рьяно ненавидят Рио Тинто. Часть II [Электронный ресурс] // ARD. 2019, 21 января. URL: http://asiarussia.ru/articles/21301/ (дата обращения: 24.02.2019).

${ }^{2}$ Постановление Правительства Республики Тыва от 24 декабря 2018 г. № 638 «О Стратегии социально-экономического развития Республики Тыва до 2030 года» [Электронный ресурс] // Официальный интернет-портал правовой информации URL: http://publication.pravo.gov.ru/File/GetFile/1700201812280002?type=pdf (дата обращения: 24.02.2019). 
Тарбастаева, И. С. (2014) Алтай и Тува: Красавица и дикарка [Электронный ресурс] // Новые исследования Тувы. № 1. URL: https://nit.tuva.asia/nit/article/view/192 (дата обращения: 24.02.2019).

Фофанов, В. П. (1986) Категория «отдельное» и статус гуманитарных наук // Проблемы гуманитарного познания / отв. ред. А. Н. Кочергин, В. П. Фофанов. Новосибирск : Наука. 335 с. С. 318-332.

Хатунцев, С. В. (2011) Лимитрофы - межцивилизационные пространства Старого и Нового света // Полис. Политические исследования. № 2. С. 86-98.

Яковенко, И. Г. (2006) Риски социальной трансформации российского общества: культурологический аспект. М. : Прогресс-Традиция. 176 с.

Hall, E. T. (1990) The hidden dimension. New York : Doubleday. 217 p.

Smith, A. D. (1986) The Ethnic Origins of Nations, Oxford : Blackwell. 329 p.

Smith, A. D. (2003) The politics of culture: ethnicity and nationalism // Companion Encyclopedia of Anthropology: Humanity, Culture and Social Life / Ed. by T. Ingold. London ; New York: Routledge. 1127 p. P. 706-734.

The Spatial Turn: Interdisciplinary Perspectives (2008) / by B. Warf \& S. Arias (Eds). New York : Routledge. $232 \mathrm{p}$.

Дата поступления: 15.06.2019 2.

\section{REFERENCES}

Anaiban, Z. V. (2011) Kharakteristika etnodemograficheskikh protsessov Tuvy v sovetskii period [Characteristics of ethnodemographic processes in Tuva during the Soviet period]. The New Research of Tuva, no. 2-3 [online] Available at: https://nit.tuva.asia/nit/article/view/412 (access date: 24.02.2019). (In Russ.).

Ahiezer, A. S. (1998) Rossiia: kritika istoricheskogo opyta: sotsio-kul'turnaia dinamika Rossii. [Russia: critique of historical experience: sociocultural dynamics of Russia]. Novosibirsk, Sibirskii hronograf. Vol. I: Ot proshlogo $\mathrm{k}$ budushhemu [From the past to the future]. $804 \mathrm{p}$. (In Russ.).

Golovkov, A. N. (2011) Prostranstvennoe razvitie kak ekonomicheskaia kategoria. Management of economic systems, no. 2 (26) [online] Available at: http://uecs.ru/uecs-26-262010/item/325-2011-03-25-11-33-26 (access date: 24.02.2019). (In Russ.).

Golovnev, A. V. (2009) Antropologiia dvizheniia [Anthropology of Motion]. Ekaterinburg, UrO RAN; Volot. 496 p. (In Russ.).

Golovnev, A. V. (2012) Lokal'nye i magistral'nye kul'tury Severnoi Evrazii [Local and mainstream cultures of Northern Eurasia]. In: Chelovek i Sever: antropologiia, arkheologiia, ekologiia [Man and the North: anthropology, archeology, ecology]. Ed. by A. N. Bagashev. Iss. 2. Tjumen', IPOS SO RAN. 425 p. Pp. 234-237. (In Russ.).

Datsyshen, V. G. (2014) Saianskii rubezh. Yuzhnaia chast' Prieniseiskogo kraia i russko-tuvinskie otnosheniia $v$ 1616-1911 gg. [The Sayan frontier. The southern part of the Yenisei region and Russian-Tuvan relations in 16161911]. Moscow, Direkt-Media. 309 p. (In Russ.).

Kriukov, V. A. (2016) Arteriia ili matritsa? [An artery or a matrix?]. ECO, no. 5, pp. 2-4. (In Russ.).

Lazhentsev, V. N. (2013) Territorial'noe razvitie kak ekonomiko-geograficheskaia deiatel'nost' (teoriia, metodologiia, praktika) [Territorial development as economic and geographical activity (theory, methodology, practice)]. Regional economy, no. 1, pp. 10-20. (In Russ.).

Lamazhaa, Ch. K. (2011) Arkhaizatsiia obshchestva v period sotsial'nykh transformatsii [The Archaization of Society in the Period of Social Transformations]. Znanie. Ponimanie. Umenie, no. 3, pp. 35-42. (In Russ.).

Lamazhaa, Ch. K. (2014) Tuva i Rossiia: 100 let vmeste [Tuva and Russia: 100 years united]. The New Research of Tuva, no. 3 [online] Available at: https://nit.tuva.asia/nit/article/view/127 (access date: 24.02.2019). (In Russ.).

Potanin, G. N. (2002) Ocherki Severo-Zapadnoi Mongolii. Vypusk 2 [Essays on the North-Western Mongolia. Issue 2]. In: Traditsionnaia kul'tura tuvintsev glazami inostrantsev (konets XIX - nachalo XX veka) [Traditional culture of Tuvans through the eyes of foreigners (late 19th - early 20th centuries)] / Preparation of texts, preface and comments by A. K. Kuzhuget. Kyzyl, Tuvan book publisher. 225 p. Pp. 18-23. (In Russ.).

Prokof'eva, E. D. (2011) Protsess natsional'noi konsolidatsii tuvintsev [The process of national consolidation of the Tuvans]. St. Petersburg, Nauka. 538 p. (In Russ.).

Rumyantsev, O. K. (2018) Prostranstvennyi povorot: otnoshenie etnosa i natsii kak analogiia otnosheniia prostranstvennogo i vremennogo modusa sub'ektivnosti cheloveka [The spatial turn: the relation of the eth- 
nos and the nation as an analogy of the relation of spatial and temporal mode of human subjectivit]. In: Tselevye orientiry gosudarstvennoi natsional'noi politiki: vozobnovlenie chelovecheskogo resursa i natsional'nye kul'tury: problema Drugogo [Targets of the state national policy: the renewal of human resource and national cultures: the problem of the Other]. Ed. by O. K. Rumyantsev and A. Iu. Shemanov. St. Petersburg, Aletheia. 358 p. Pp. 137-159. (In Russ.).

Sorokin, P. A. (1992) Chelovek. Civilizatsiia. Obschestvo [Man. Civilization. Society]. Moscow, Politizdat. 543 p. (In Russ.).

Sorokin, P. A. (2005) Sotsiologiia revoliutsii [Sociology of revolution]. Moscow, ROSSPEN. 704 p. (In Russ.).

Tarbastaeva, I. S. (2014) Altai i Tuva: Krasavitsa i dikarka [Altai and Tuva: the beauty and the savage]. The New Research of Tuva, no. 1 [online] Available at: https://nit.tuva.asia/nit/article/view/192 (access date: 24.02.2019). (In Russ.).

Fofanov, V. P. (1986) Kategoriia «otdelnoe» i status gumanitarnykh nauk [The category of "individual" and the status of the humanities]. In: Problemy gumanitarnogo poznaniia [Problems of humanitarian knowledge] / Ed. by A. N. Kochergin and V. P. Fofanov. Novosibirsk, Nauka. 335 p. Pp. 318-332. (In Russ.).

Hatuntsev, S. V. (2011) Limitrofy - mezhtsivilizatsionnye prostranstva Starogo i Novogo sveta [Limitrophes, the intercivilizational expanses of the Old and New worlds]. Polis. Political Studies, no. 2, pp. 86-98. (In Russ.).

Yakovenko, I. G. (2006) Riski sotsial'noi transformatsii rossiiskogo obschestva: kul'turologicheskii aspekt [Risks of social transformation of Russian society: the cultural aspect]. Moscow, Progress-Traditsiia. 176 p. (In Russ.).

Hall, E. T. (1990) The hidden dimension. New York : Doubleday. 217 p.

Smith, A. D. (1986) The ethnic origins of nations. Oxford : Blackwell. 329 p.

Smith, A. D. (2003) The politics of culture: ethnicity and nationalism. In: Companion encyclopedia of anthropology: Humanity, culture and social life / Ed. by T. Ingold. London, New York, Routledge. 1127 p. P. 706-734.

The spatial turn: Interdisciplinary perspectives (2008) / Ed. by B. Warf and S. Arias. New York, Routledge. $232 \mathrm{p}$.

Submission date: 12.06 .2019$. 